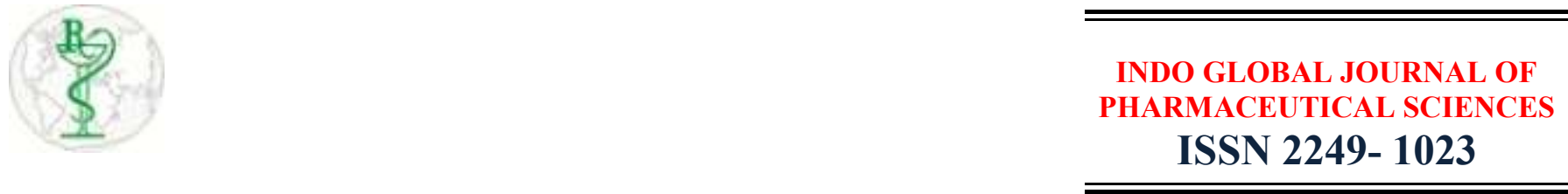

\title{
Cloning of Phosphate Starvation Response 1gene (AtPHR1) in Garden Plants: Focus on Phytoremediation of Inorganic Phosphate
}

\author{
Anubhuti Gupta, Vibha Rani * \\ Jaypee Institute of Information Technology, Noida, India
}

Address for Correspondence: Vibha Rani, vibha.rani@jiit.ac.in

\begin{abstract}
Keywords
Phytoremediation;

Transgenic Plant;

Transformation;

Hyperaccumulation

; Inorganic

Phosphate.
\end{abstract}

\begin{abstract}
Eutrophication caused by inflow of excess amounts of nutrients from agricultural run-off, sewage, industrial effluents and rapid growth of phytoplankton causing algal blooms is a major factor contributing to water pollution resulting in exhaustion of oxygen and build up of toxic cyanotoxins. Phytoremediation is an efficient, low cost and sustainable method to combat this problem in aquatic environment. Transgenic plants containing AtPHR1 gene were created with the introduction of gene into the garden plants torenia, petunia and verbena and its overexpression to enhance $\mathrm{Pi}$ absorption rate was studied. It was found that the phosphorus concentration in leaves of transgenic plants as compared to the control host plants were 2-3 folds higher in all the 3 plant species. The Pi absorption rate observed in transgenic plant was up to $0.091 \mathrm{mgP} / \mathrm{day} / \mathrm{plant}$ as compared to $0.056 \mathrm{mgP} / \mathrm{day} / \mathrm{plant}$ in host. Overexpression of AtPHR1 does not retard plant growth as no statistically significant difference in biomass of transgenic and host plants were observed suggesting the excessive absorbed $\mathrm{Pi}$ is accumulated and stored in the aerial part of the plants and not used for its growth. Also, no morphological or reproductive abnormalities, due to overexpression of gene were observed which showed that AtPHR1 gene can enhance Pi accumulation with no negative effects on plant growth. Death in certain portions of leaves may be due to the exceeding the critical limit of Pi accumulation since Pi may cause cell toxicity. Thus transgenic plants can be used as an effective phyotoremediation solution to the polluted aquatic environment and for the recovery of Phosphorus which is expected to be exhausted as a natural resource within a hundred year.C 2016 iGlobal Research and Publishing Foundation. All rights reserved.
\end{abstract}

Conference Proceedings: International Conference on Advances in Plant and Microbial Biotechnology (PMB2017); JIIT, Noida: February 02-04, 2017

Indo Global Journal of Pharmaceutical Sciences( ISSN 22491023 ; CODEN- IGJPAI; NLM ID: 101610675) indexed and abstracted in EMBASE(Elsevier), SCIRUS(Elsevier),CABI, CAB Abstracts, Chemical Abstract Services(CAS), American Chemical Society(ACS), Index Copernicus, EBSCO, DOAJ, Google Scholar and many more. For further details, visit http://iglobaljournal.com 